Supplement of Atmos. Chem. Phys., 15, 1411-1420, 2015

http://www.atmos-chem-phys.net/15/1411/2015/

doi:10.5194/acp-15-1411-2015-supplement

(C) Author(s) 2015. CC Attribution 3.0 License.

(c) (i)

Supplement of

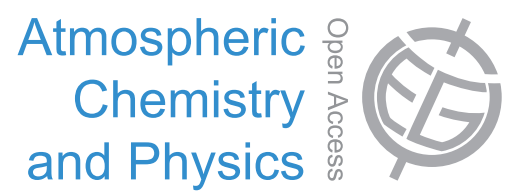

\title{
Annual cycles of organochlorine pesticide enantiomers in Arctic air sug- gest changing sources and pathways
}

T. F. Bidleman et al.

Correspondence to: T. F. Bidleman (terry.bidleman@umu.se) 
Enantiomer separations of $\alpha-\mathrm{HCH}, \mathrm{TC}$ and CC were carried out on Betadex-120 (BDX, $20 \%$ permethylated $\beta$-cyclodextrin in SPB-25, $30 \mathrm{~m} \times 0.25 \mathrm{~mm}$ i.d., $0.25 \mu \mathrm{m}$ film, Supelco, Bellefonte, PA, U.S.A.) or BGB-172 (BGB, 20\% tert-butyldimethylsilyl- $\hat{a}-$ cyclodextrin in OV-1701,15 m x 0.25 mm i.d., $0.25 \mu \mathrm{m}$ film, BGB Analytik AG, Switzerland), with detection by electron capture negative ion mass spectrometry. Instruments used were a Hewlett-Packard 5890 GC-5989 MS-Engine (Hewlett-Packard, U.S.A.) or Agilent 6890 GC-5973 Mass Selective Detector (MSD). Operating conditions were: injector (splitless, opened after $1 \mathrm{~min}$ ) $220^{\circ} \mathrm{C}$, ion source $150^{\circ} \mathrm{C}$, quadrupole 100 ${ }^{\circ} \mathrm{C}$, helium carrier gas at 40-60 $\mathrm{cm} \mathrm{s}^{-1}$, methane reagent gas. Temperature programs were varied according to the analytes and condition of the column. In general, slower ramp times and/or lower oven temperatures were used to improve enantiomer resolutions on aged columns. Typical programs were (Kurt-Karakus et al., 2005):

- Chlordanes on BDX: $90{ }^{\circ} \mathrm{C}(1 \mathrm{~min}), 15^{\circ} \mathrm{C} \min ^{-1}$ to $150{ }^{\circ} \mathrm{C}, 1{ }^{\circ} \mathrm{C} \min ^{-1}$ to $185^{\circ} \mathrm{C}(25$ $\min ), 20{ }^{\circ} \mathrm{C} \min ^{-1}$ to $225^{\circ} \mathrm{C}$ (20 min).

- Chlordanes and $\alpha$-HCH on BGB: $90^{\circ} \mathrm{C}(1 \mathrm{~min}), 20^{\circ} \mathrm{C} \min ^{-1}$ to $160{ }^{\circ} \mathrm{C}, 2{ }^{\circ} \mathrm{C} \min ^{-1}$ to $180{ }^{\circ} \mathrm{C}$ (41 min), $25^{\circ} \mathrm{C} \mathrm{min}{ }^{-1}$ to $225^{\circ} \mathrm{C}$ (15 min).

- $\alpha$-HCH on BDX: $90{ }^{\circ} \mathrm{C}(1 \mathrm{~min}), 20{ }^{\circ} \mathrm{C} \mathrm{min}^{-1}$ to $145^{\circ} \mathrm{C}, 1{ }^{\circ} \mathrm{C} \min ^{-1}$ to $170{ }^{\circ} \mathrm{C}, 20{ }^{\circ} \mathrm{C}$ $\min ^{-1}$ to $225^{\circ} \mathrm{C}(15 \mathrm{~min})$.

Chromatographic peaks were integrated manually at each of the two monitored ions.

Target/qualifier ion ratios (IRs) for each enantiomer peak were required to fall within the 95\% C.I. of IRs for standards, otherwise, the result was rejected (Kurt-Karakus et al., 2005). 

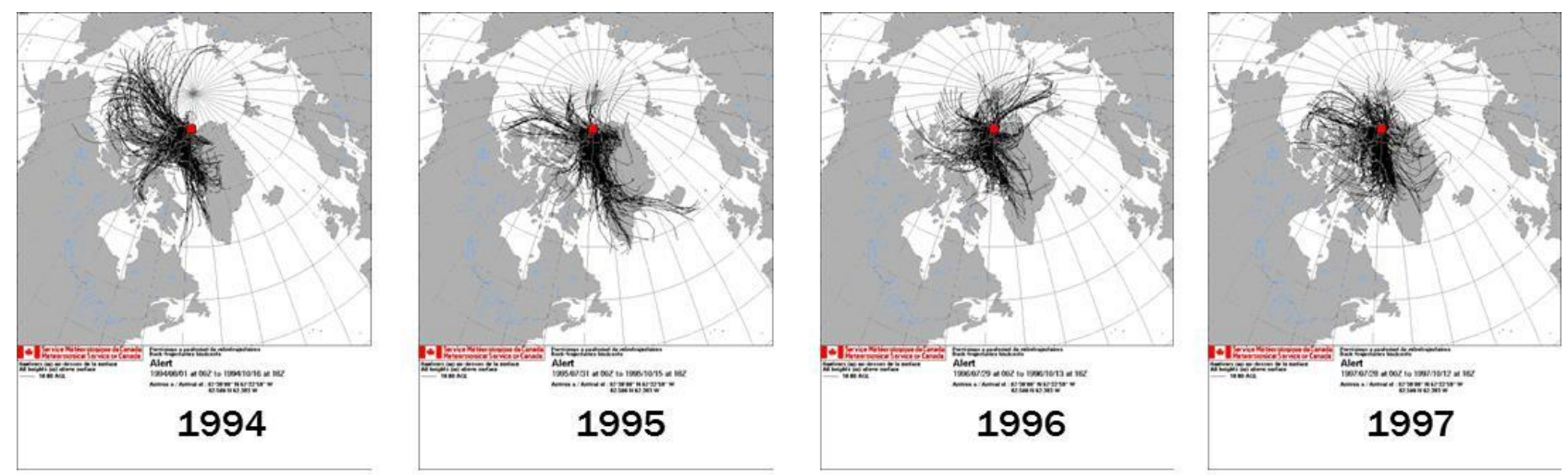

1
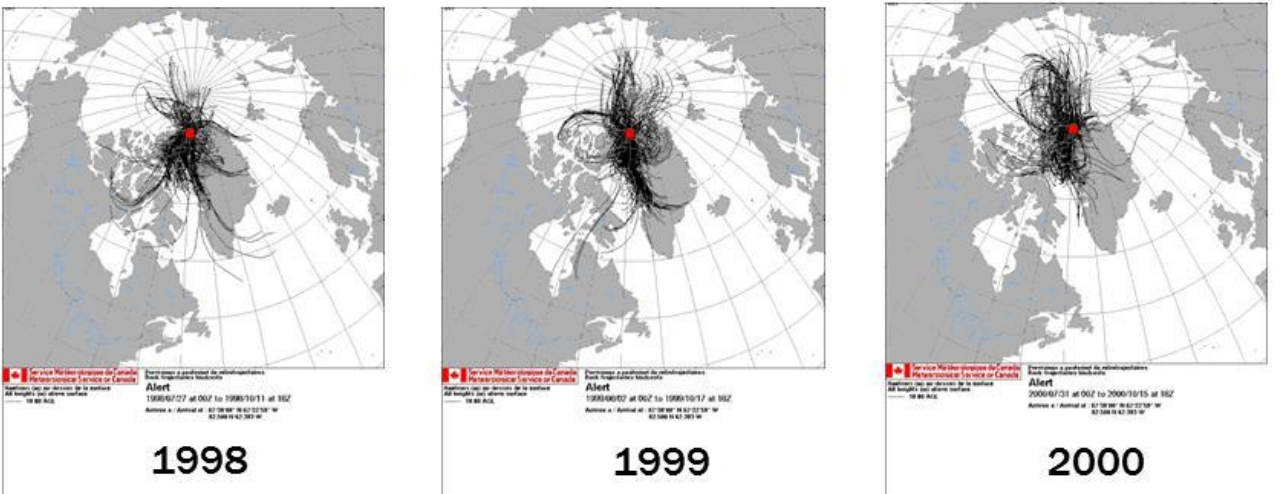

Figure S1. Air parcel trajectories $72 \mathrm{~h}$ backward from Alert (red square) and at $10 \mathrm{~m}$ height for July 31-August 1 to October 15 (weeks 31-42) (Canadian Meteorological Centre). 

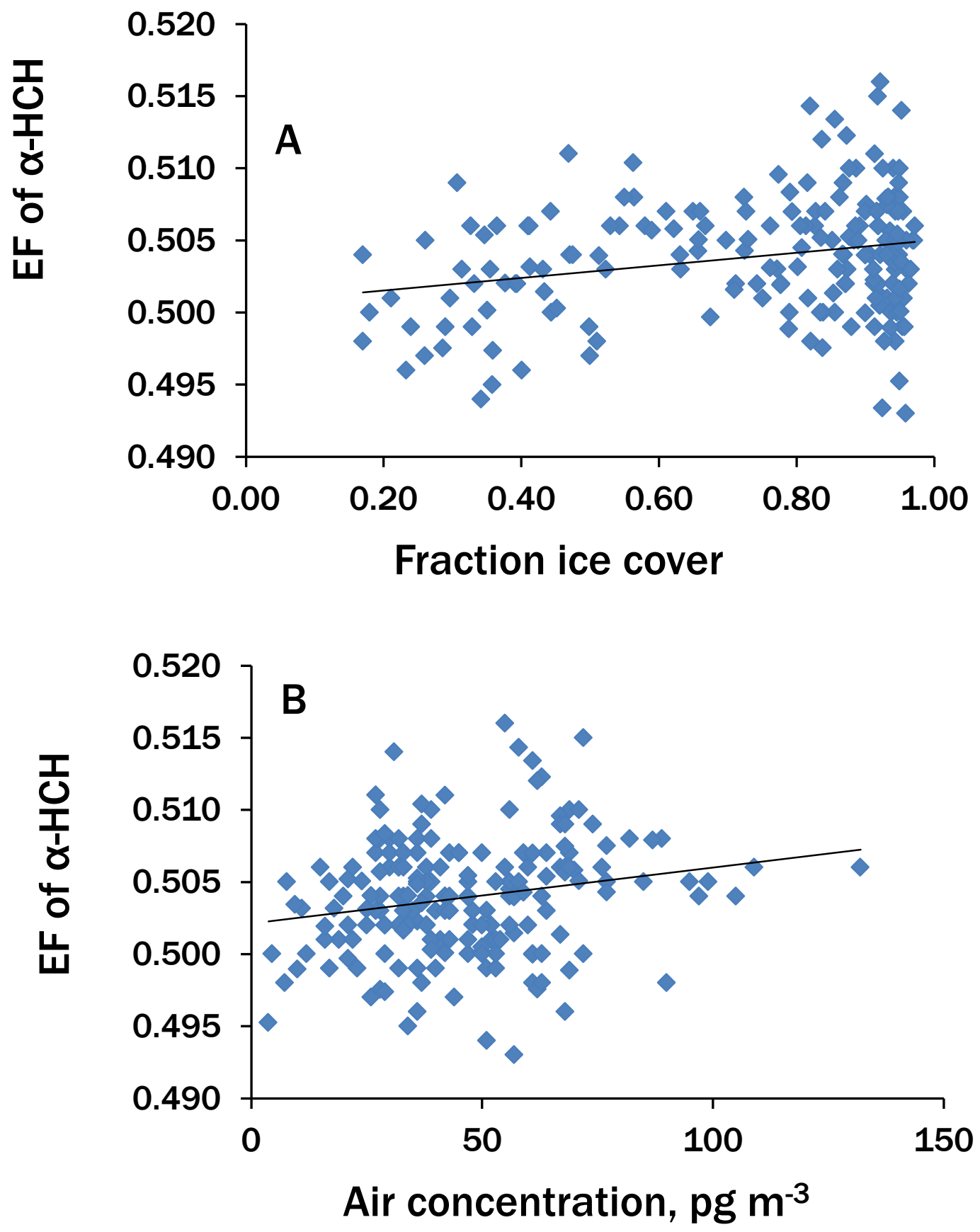

Figure S2. EFs of $\alpha-\mathrm{HCH}$ versus fraction of ice cover in the Canadian Archipelago and southern Beaufort Sea $\left(A, r^{2}=0.061\right)$ and air concentration $\left(B, r^{2}=0.042\right)$. 

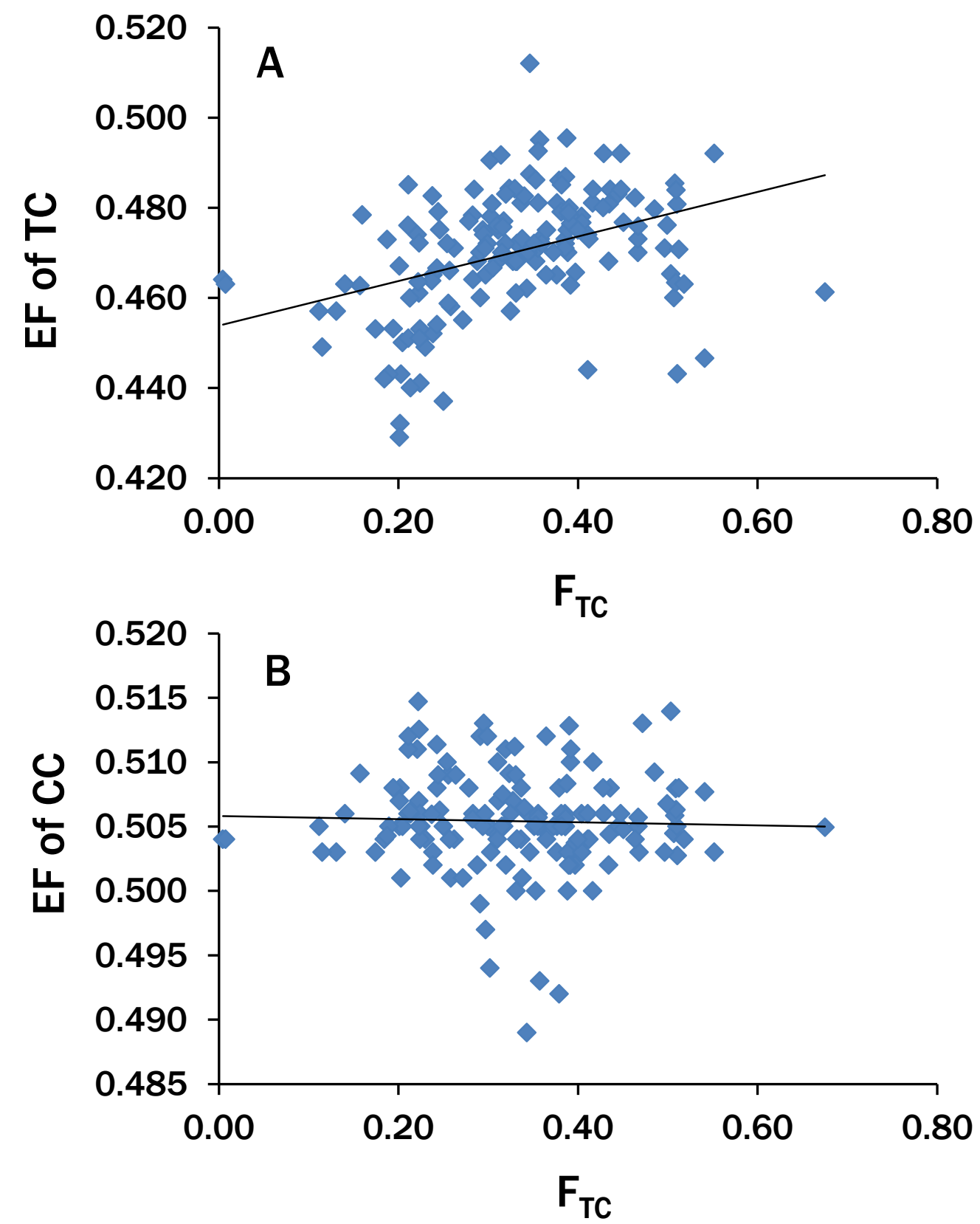

2

Figure S3. EFs of TC $\left(\mathrm{A}, \mathrm{r}^{2}=0.16\right)$ and $\mathrm{CC}\left(\mathrm{B}, \mathrm{r}^{2}=0.0012\right)$ versus fraction of $\mathrm{TC}, \mathrm{F}_{\mathrm{TC}}=$ TC/(TC+CC). 

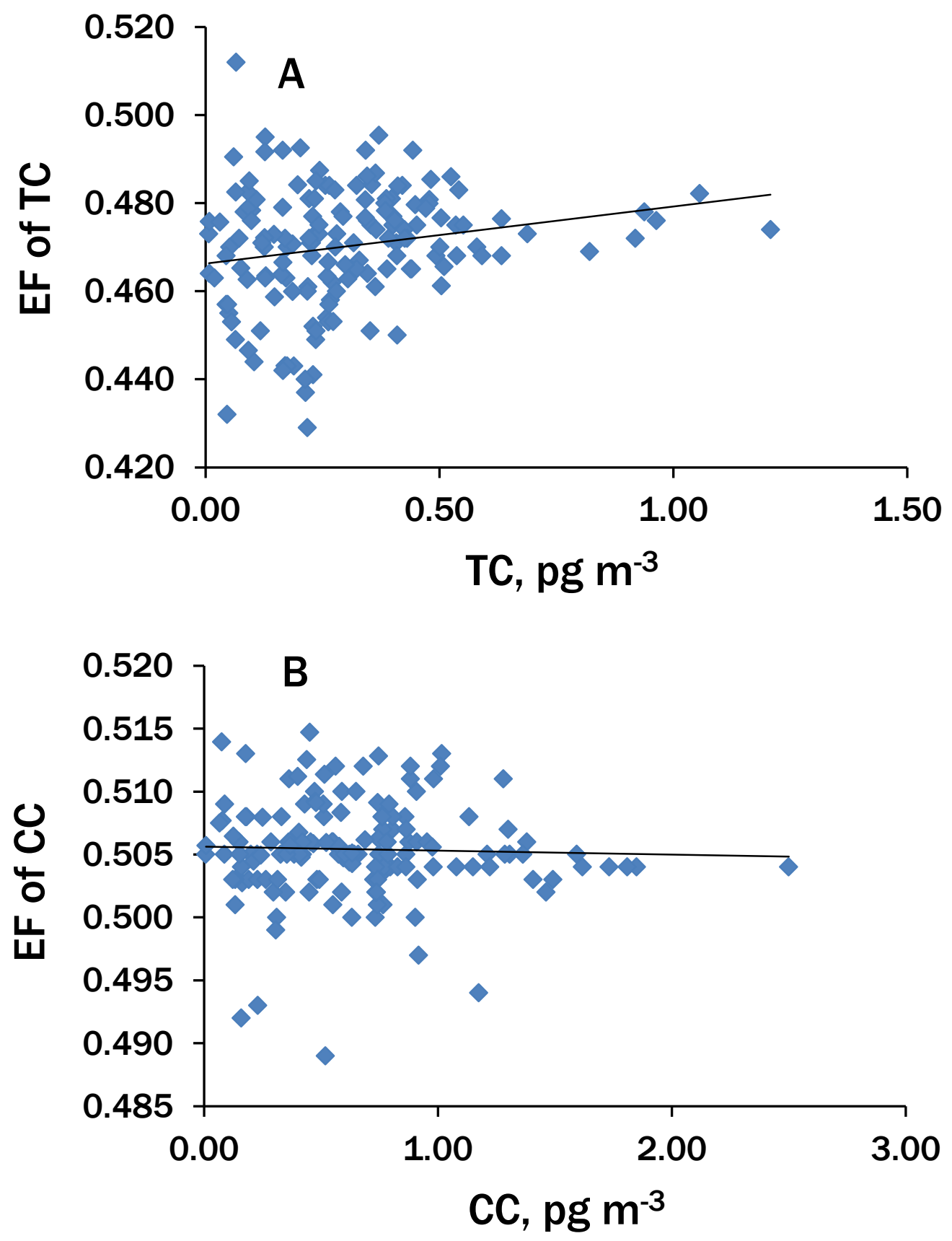

Figure S4. EFs of TC $\left(A, r^{2}=0.039\right)$ and $\mathrm{CC}\left(\mathrm{B}, \mathrm{r}^{2}=0.0012\right)$ versus air concentrations. 

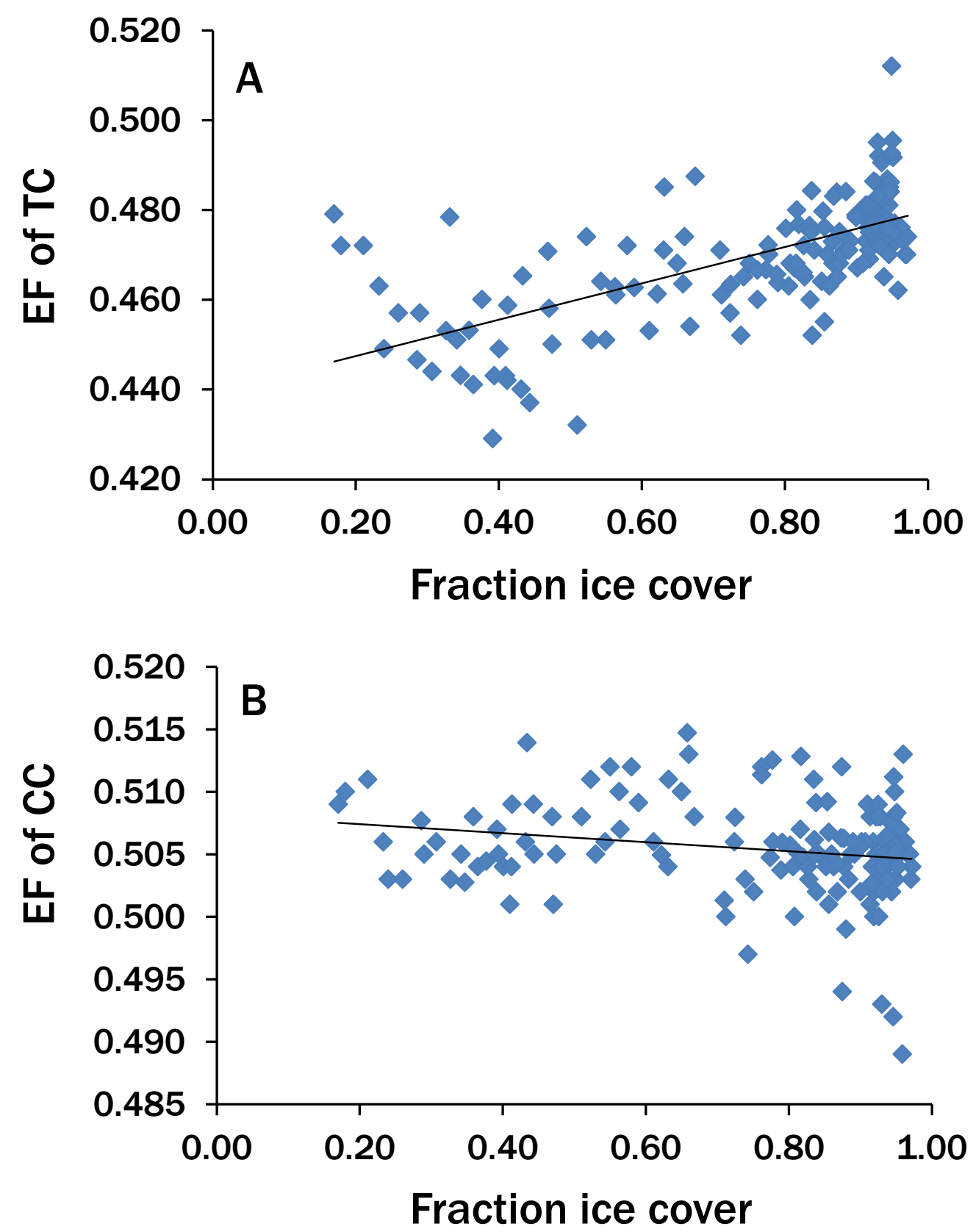

1

3 Figure S5. EFs of TC $\left(A, r^{2}=0.44\right)$ and CC $\left(B, r^{2}=0.044\right)$ versus fraction of ice cover in 4 the Canadian Archipelago and southern Beaufort Sea. 


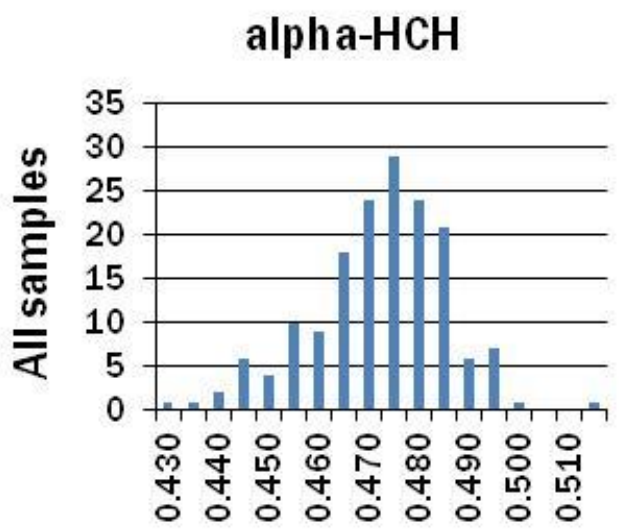

alpha-HCH

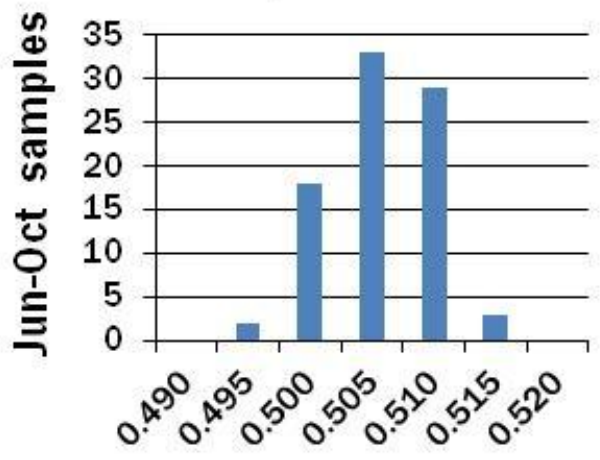

alpha-HCH

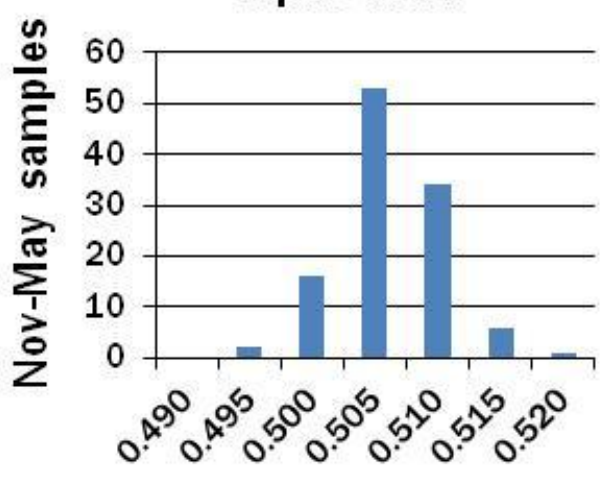

cis-chlordane

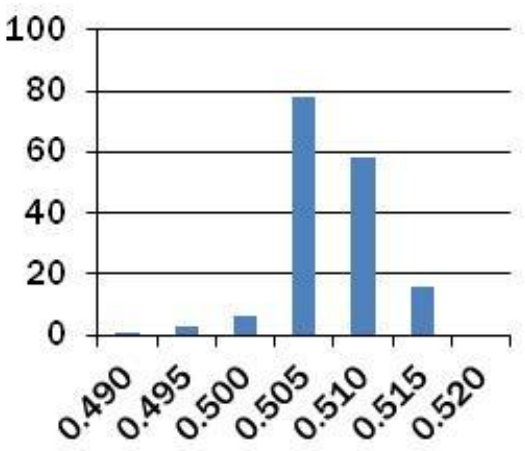

Enantiomer fraction

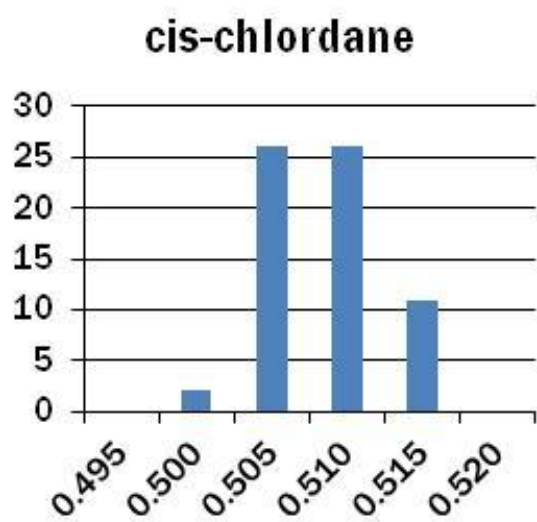

Enantiomer fraction

cis-chlordane

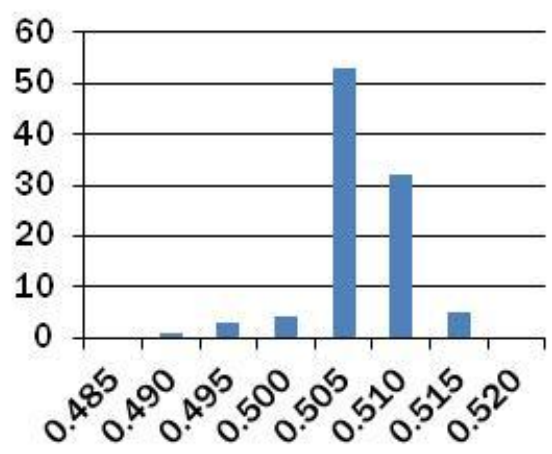

Enantiomer fraction trans-chlordane

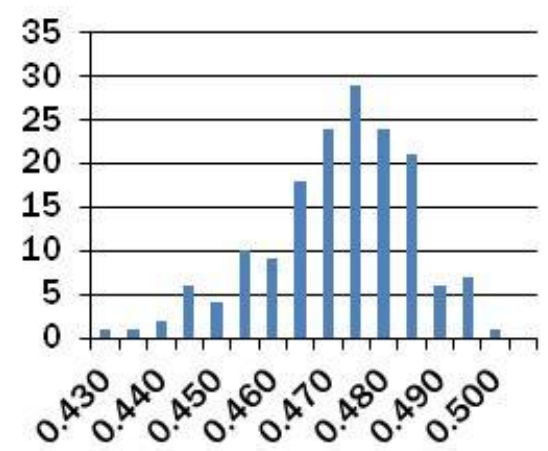

trans-chlordane

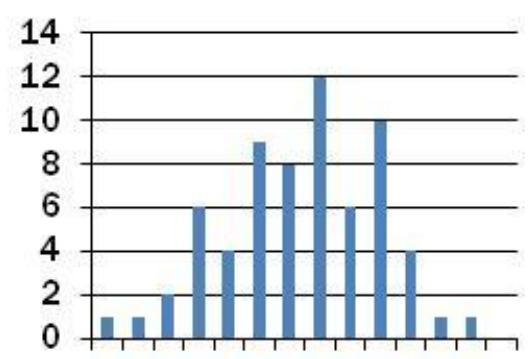

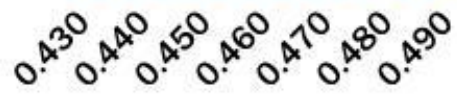

trans-chlordane

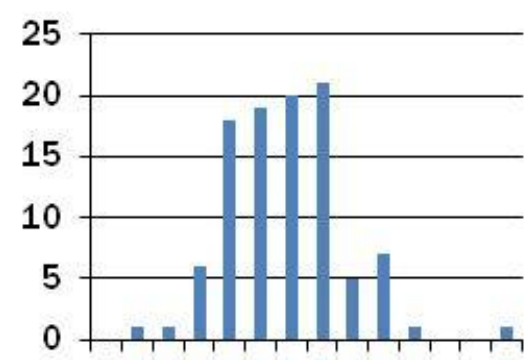

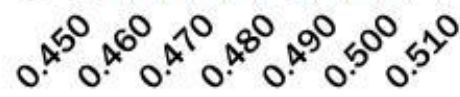

